\title{
Micro-Scale Patterning of Ceramic Colloidal Suspension by Micro Molding in Capillaries (MIMIC) with Assistance of Highly Infiltrating Liquid
}

\author{
Junko IMASU, Hiroshi FUDOUZI* and Yoshio SAKKA
}

Nano Ceramics Center, National Institute for Materials Science, 1-2-1, Sengen, Tsukuba-shi 305-0047

*Optronic Materials Center, National Institute for Materials Science, 1-2-1, Sengen, Tsukuba-shi 305-0047

\author{
Micro Molding in Capillaries (MIMIC) 法に高浸透性液体の毛管力を利用した \\ セラミックコロイドサスペンションのマイクロパターニング \\ 今須淳子 ·不動寺 浩* ·目 義雄 \\ 物質・材料研究機構 ナノセラミックスセンター，305-0047 茨城県つくば市千現 1-2-1 \\ *物質・材料研究機構 光材料センター, 305-0047 茨城県つくば市千現 1-2-1
}

\begin{abstract}
This paper describes the fabricating of ceramic micro-scale patterns over a wide area using colloidal suspensions of ceramic powders in the improved Micromolding in Capillaries (MIMIC) method. As the patterning mechanism is based on capillary actions of suspensions, the MIMIC process has a difficulty in that the patterning lengths are determined by the characteristics of the suspensions. For fabricating a striped pattern of long lines with various suspensions, we added a new process of second capillary action of liquids with a high infiltration characteristic after existing MIMIC process, so that the suspensions were moved farther inside with the strong capillary force arising from the liquids which afterward infiltrate. In addition, by repeating the series of capillary actions of suspensions and infiltrating liquids, we could double the patterned lengths of the tin oxide. This study demonstrates the possibility of wide-area patterning of a suspension that is not likely to voluntarily infiltrate with improved MIMIC process.

[Received June 3, 2006; Accepted July 20, 2006]
\end{abstract}

Key-words : Micro-patterning, Soft-lithography, Capillarity, Ceramic colloidal suspension, Infiltration, Tin oxide, Micro molding

\section{Introduction}

Micro-scale patterning of electro-ceramics is of increasing significance in association with the recent miniaturization and integration of electro-devices. Therefore, nowadays, various techniques such as UV and X-ray Lithography, ${ }^{1,2}$ ) Laser Ablation, ${ }^{3)}$ Inkjet-Printing, ${ }^{4)}$ Aerosol Deposition, ${ }^{5)}$ and Micromolding in Capillaries (MIMIC) ${ }^{6)-9)}$ are under development for the manufacturing and fabricating of micro-scale ceramic structures.

Among such techniques, MIMIC is considered to contribute to the low-cost and mass-production of micro-patterned ceramic devices. This is one of the soft-lithographies introduced by Whitesides et al. as simple and easy techniques for micro-scale patterning using flexible micro-molds. ${ }^{10)-12)}$ These micro-molds are manufactured by repeatedly replicating a master-mold with elastomers such as Poly-dimethylsiloxane (PDMS), and the master-mold is fabricated by ordinary lithography on a silicone wafer. Therefore, many of the same structures can be easily fabricated from one master-mold. Of all the other soft-lithographies, MIMIC has some advantages based on its patterning mechanism of capillarity. ${ }^{13), 14)}$ They are applicable for variable fluids, the simple procedure consisting of only one step, and the capability to generate structures of required thicknesses. Consequently, MIMIC is regarded as the technique which is suited for the massproduction of arbitrary micro-scale structures.

Applying ceramic fluids to the MIMIC has been studied in two main categories according to the starting materials. The one study used polymeric or sol-gel precursors for the oxide ceramics. ${ }^{6,7)}$ In this case, patterning over a wide area is possible for the precursor smoothly infiltrates farther into the channels of the molds. However, there is one problem of form shrinking upon heat treatment to volatilize the remaining organic components. The other study is using colloidal suspensions of ceramic powders developed by Heule et al. ${ }^{8)}$ By using commercial ceramic powders, high-purity structures are easily generated at a low-cost in this process. However, there was a problem that the infiltration length was short, because the suspensions are non-Newtonian fluids, and the solvents of the suspension continuously evaporate during the process and the suspensions are gradually condensed. ${ }^{8)}$ Therefore, the Vacuum-Assist method was introduced. $\left.{ }^{9)}, 15\right)$ This method enabled the fabrication of defect-free micro-scale patterns in a $\mathrm{mm}$-scale area. However, the shapes of the structures may be restricted to vacuum aspiration.

We have been studying how to fabricate a uniform pattern over a wide area by the process of capillarity, by applying a ceramic colloidal suspension to the MIMIC. In this study, we added a new process of second capillary action after suspensions voluntarily infiltrated with their own capillary force. In this new step, we dropped a liquid with a high infiltration characteristic for the materials of the molds in front of the mold channels, so that the suspensions moved farther into the mold due to the strong capillary force arising from the dropped liquid. If we then choose a highly-volatile liquid as this infiltrating liquid, the next drop of the suspension is possible after volatilization of the infiltrating liquid. By repeating this process, a consecutive long pattern would be fabricated. We now report that we fabricated a stripe pattern of double length by repeating this process 3 times. This result demonstrates the effectiveness of the improved MIMIC process to the patterning over a wide area. 


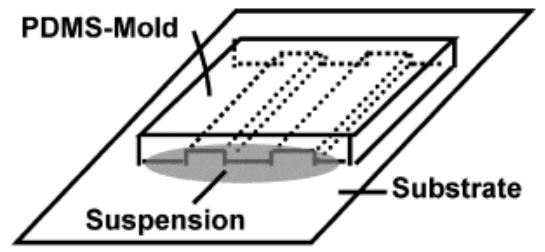

Suspension Fills Channels by Capillarity

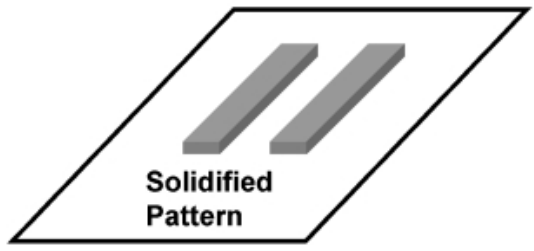

Fig. 1. Schematic of existing MIMIC.

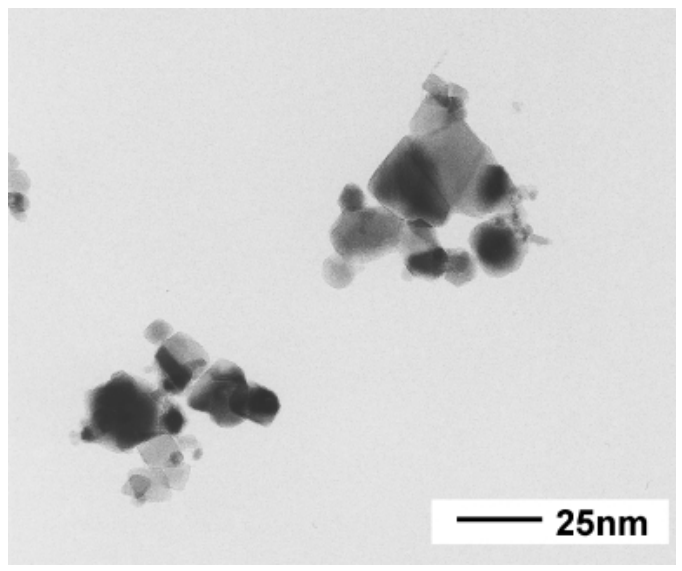

Fig. 2. TEM image of $\mathrm{SnO}_{2}$ particles.

\section{Experimental}

Figure 1 shows a schematic of the typical MIMIC process. The micro-mold was pressed on a substrate. The suspension was placed at the entrance of the micro-mold channels. After the channels were filled by capillary action and its inside dried, the micro-mold was peeled away. In this experiment, the micro-molds were made using the PDMS elastomer kit (Sylgard 184, Dow Corning, Inc., USA). The shape of the channel was a line $9.5 \mu \mathrm{m}$ in width and $1.5 \mu \mathrm{m}$ in height. The substrate was a silicon wafer (N-Type (100), coated with a $1 \mu$ m-thick oxide film, Furuya Metal Co., Ltd., Tokyo). Commercially available tin oxide angular powder (NanoTek, KANTO Chemical Co., Inc., Tokyo) was used for the ceramic colloidal suspension in this study. The BET surface area is $23 \mathrm{~m}^{2} / \mathrm{g}$, and the particle size calculated from this BET surface area is $37 \mathrm{~nm}$ under the assumption that the particle is sphere. The calculated particle size is similar to the size observed by TEM (Fig. 2), where it is seen that the powder has an angular type morphology and not heavily aggregated. The suspension was prepared by dispersing $2.0 \mathrm{~g}$ of this tin oxide powder in $15 \mathrm{ml}$ of ethanol by ultrasonication for more than 10 min which results in a $2 \mathrm{vol} \%$ solid loading. The zeta-potential of the powder in the suspension was measured using an acoustic and electroacoustic spectrometer (DT-1200, Dispersion Technology Co., Ltd., USA). ${ }^{16)}$ The viscosity of the suspension was determined using a viscometer (RC-500, Toki Sangyo Co., Ltd., Japan).

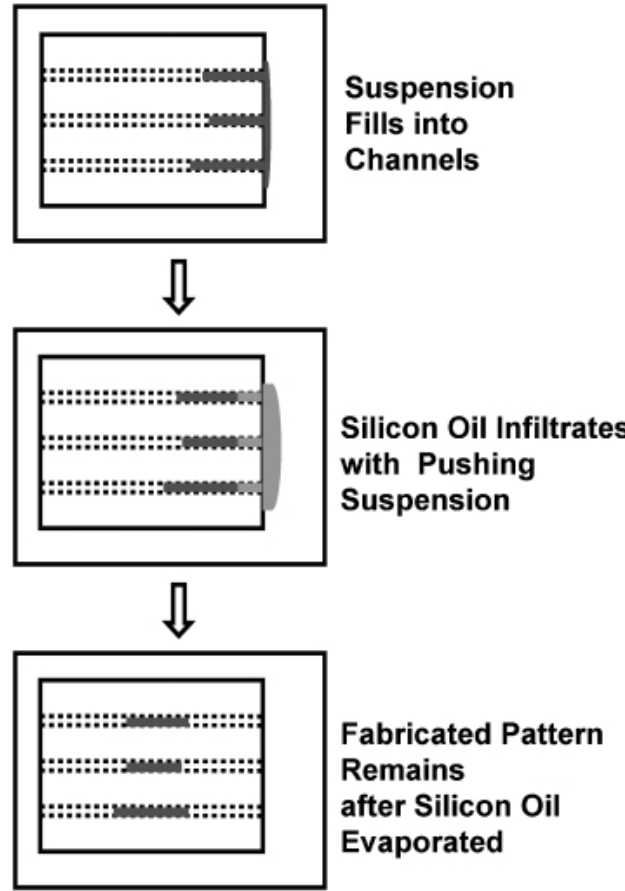

Fig. 3. Schematic of the procedure of improved MIMIC process.

Figure 3 shows a schematic diagram of the improved MIMIC process using a highly infiltrating liquid. Its procedure is as follows. The suspension is first dropped in front of the channels and fills them by capillary action. Next, the highly infiltrating liquid is dropped before the suspension dries out. The strong capillary force of the infiltrating liquid then moves the suspension farther into the mold channels. These steps are the sequence for the improved procedure. However, when the infiltrating liquid is highly-volatile, its vapor will go outside through the poromeric PDMS mold and the room for the next suspension increases at the entrance side. Therefore, this procedure can be continuously repeated. In this experiment, we used a highly volatile silicone oil (Toray Dow Corning Silicone Co., Ltd., SH200, $0.65 \mathrm{cs}$ ) as the infiltrating liquid. We repeated this procedure 3 times except for the last drop of the silicone oil for the demonstration.

\section{Result}

Recently, improvement in the dispersibility by the addition of a phosphoric ester was reported, ${ }^{17), 18)}$ though in this case, the $\mathrm{SnO}_{2}$ particles dispersed better without the phosphoric ester. The $2 \mathrm{vol} \%$ ethanol suspension acted as a Newtonian fluid and the viscosity was determined to be $9.2 \mathrm{mPas}$ at $25^{\circ} \mathrm{C}$. The zeta-potential of the suspension without dilution was 47 $\mathrm{mV}$, which indicates that the suspension is well-dispersed.

Figure 4 shows the SEM images of suspension displacement after a single procedure. In Fig. 4(a), as the rightmost solid is the solidified suspension outside the mold, the striped pattern is found about $400 \mu \mathrm{m}$ away to the left. This is the result of the capillary action of the silicone oil. Among the several kinds of liquids we tried, the silicone oil contributed the best to the displacement of the suspension as will discussed later. Fig. 4(b) shows the magnified SEM image around the boundary of the suspension and the silicone oil, inclined at a 40 degree angle. The edges of the $\mathrm{SnO}_{2}$ structure are vertical to the substrate, and this indicates that the suspension was pushed by silicone oil while maintaining the distinct boundary. 

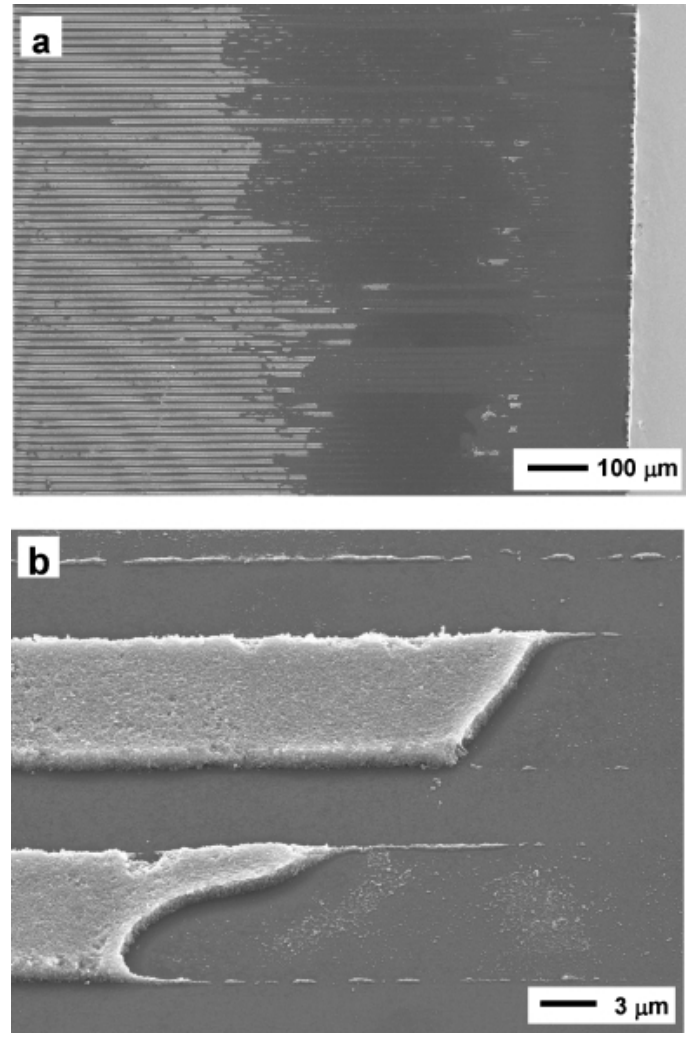

Fig. 4. SEM images of $\mathrm{SnO}_{2}$ structures after the silicone oil infiltrated. (a) Entire image signifying displacement of $\mathrm{SnO}_{2}$ pattern. (b) Magnified image around the boundary of the suspension and silicone oil.
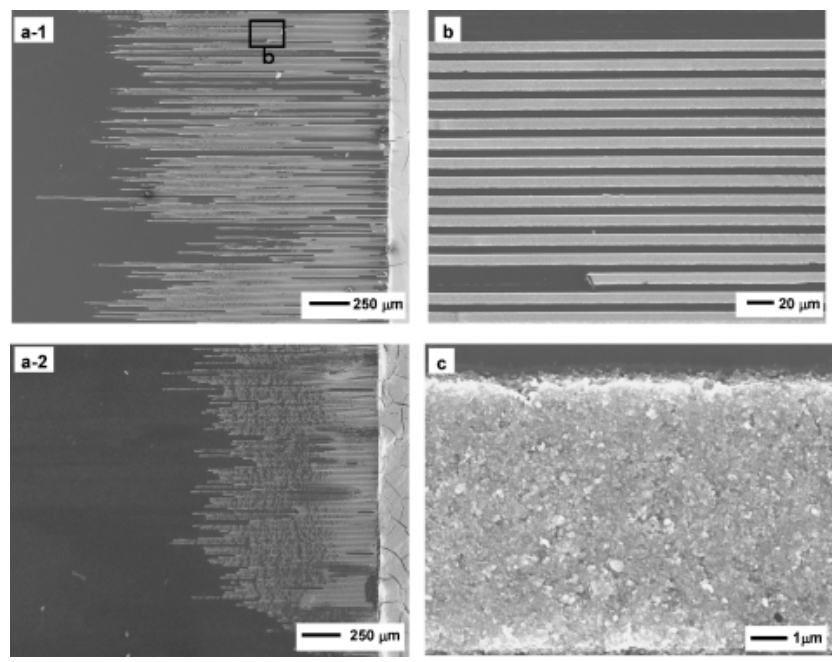

Fig. 5. (a) SEM image of the entire $\mathrm{SnO}_{2}$ pattern fabricated by (a-1) 3 repeats of improved procedure. (a-2) existing procedure. (b) Typical patterned section of (a-1). (c) Magnified image of a line of (a-1).

Figure 5 shows the characteristic of the pattern fabricated by the entire process of repeating the improved procedure 3 times except for the last drop of the silicone oil. Figure 5 (a) shows SEM images comparing the patterns fabricated by this process (Fig. 5(a-1)) and the existing procedure (Fig. 5 $(\mathrm{a}-2))$. The lengths of the fabricated lines are doubled by

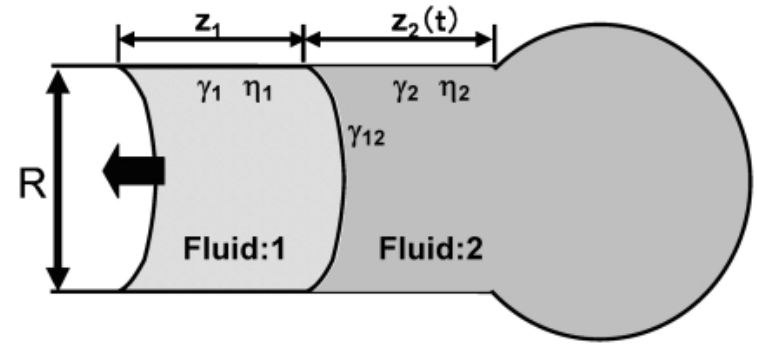

Fig. 6. Schematic of capillarity of two kinds of fluids.

the improved process. Furthermore, fabrication of a longer pattern would be possible by increasing the number of cycles. From the SEM images of the typical patterned section of Fig. 5(a-1), we can see that the pattern consisted of separate lines (Fig. 5(b)) and the powders densely fill the structure (Fig. 5(c)).

Additionally, we tried some kinds of solvents of suspensions and infiltrating liquids. However, the $\mathrm{SnO}_{2}$ particles did not dispersed well in other solvents, and for infiltrating liquids, only this highly volatile silicone oil was usable to make continuous and clear patterning.

\section{Discussion}

We now discuss the capillary action for the two kinds of fluids that enter a capillary in sequence and the choice of the infiltrating liquid.

At first, the dynamics when one kind of liquid slowly infiltrates into a horizontal cylindrical capillary is explained by Washburn's law, ${ }^{19)}$ which is described that the capillary force $F$ and the viscous force $F_{\eta}$ are equal. In this case, the capillary force is written as $F=2 \pi R\left(\gamma_{\mathrm{V}}-\gamma_{\mathrm{L}}\right)$, while the viscous force is calculated using Poiseuille's law as $F_{\eta}=8 \pi \eta z(t) \cdot \mathrm{d} z(t) / \mathrm{d} t$. So, the dynamic equation is written like this: $2 \pi R\left(\gamma_{\mathrm{V}}-\gamma_{\mathrm{L}}\right)=$ $8 \pi \eta z(t) \cdot \mathrm{d} z(t) / \mathrm{d} t$. Here, $R$ is the radius of the cylindrical capillary, $\gamma_{\mathrm{V}}$ and $\gamma_{\mathrm{L}}$ are the wall-vapor and wall-liquid interfacial free energies, respectively, $\eta$ is the viscosity and $z(t)$ is the length of the infiltration of the liquid at time $t$. This dynamic equation is solved about $z(t)$ as: ${ }^{8), 13), 19)}$

$$
z(t)=\left(\frac{R \cdot\left(\gamma_{\mathrm{V}}-\gamma_{\mathrm{L}}\right) \cdot t}{2 \eta}\right)^{1 / 2}
$$

Figure 6 shows a schematic of the capillary action of two kinds of fluids, Fluid 1 and Fluid 2 that sequentially infiltrate. $\gamma_{1}, \gamma_{2}$ and $\gamma_{12}$ are the interfacial free energies between the wallFluid 1, wall-Fluid 2, and Fluid 1-Fluid 2, respectively. In addition, $\eta_{1}$ and $\eta_{2}$ are the viscosities of Fluid 1 and 2 , respectively. The capillary force of Fluid 2 is written as $F=2 \pi R\left(\gamma_{1}-\right.$ $\left.\gamma_{2}\right)$, in the case when the fluids completely separate $\left(\gamma_{12} \gg 0\right)$, and the viscous force is described by Poiseuille's law; $F_{\eta}=8 \pi$ $\left(\eta_{1} z_{1}+\eta_{2} z_{2}(t)\right) \cdot \mathrm{d} z_{2}(t) / \mathrm{d} t$, if Fluid 2 begins to infiltrate when Fluid 1 arrives at $z_{1}$. When this entire system is assumed to mainly move by the capillary force of Fluid 2, Formula (1) is rewritten as Formula (2), by solving the dynamic equation described using Washburn's law as $2 \pi R\left(\gamma_{1}-\gamma_{2}\right)=8 \pi\left(\eta_{1} z_{1}+\right.$ $\left.\eta_{2} z_{2}(t)\right) \cdot \mathrm{d} z_{2}(t) / \mathrm{d} t$ :

$$
z_{2}(t)=\left(\frac{R \cdot\left(\gamma_{1}-\gamma_{2}\right) \cdot t}{2 \eta_{2}}+A^{2}\right)^{1 / 2}-A
$$

where $A=\eta_{1} z_{1} / \eta_{2}$. Here, $z_{2}(t)$ is the length of the infiltration of Fluid 2 when time t passed after Fluid 2 began to enter. Formula (2) indicates that when $\gamma_{1}-\gamma_{2}>0$, the entire system is 


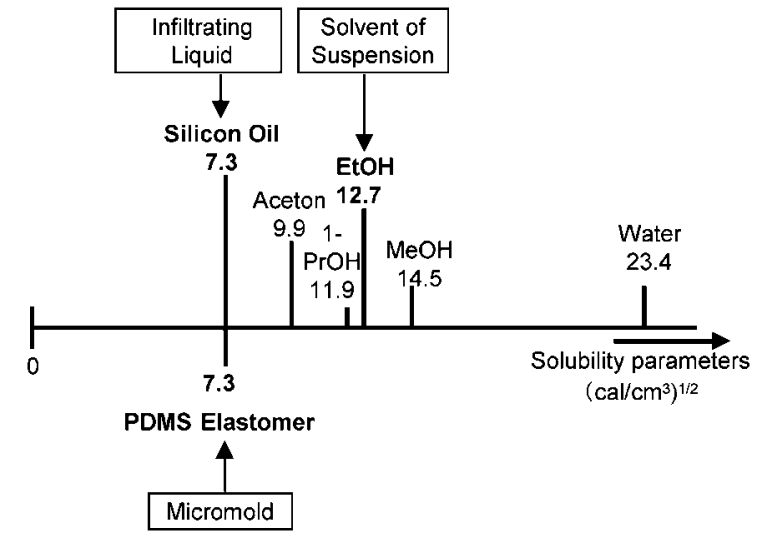

Fig. 7. Graph of solubility parameters of typical solvents and PDMS. The horizontal scale represents the magnitude of the parameters.

able to move into the capillary. As in our study, the viscosity of the ethanol suspension increased during the process and the shape of the capillary was a flat quadrangular prism, Formula (2) cannot be directly used. However, it is considered that the fluids move forward when the infiltrating liquid is chosen based on the following conditions:

$$
\gamma_{12} \gg 0 \text { and } \gamma_{1}-\gamma_{2} \gg 0 \text {. }
$$

For the choice of the infiltrating liquid, we used solubility parameters as standards of the infiltration characteristic, ${ }^{20)}$ for the interfacial free energies between the liquids and PDMS are not widespread. The solubility parameter of Liquid $i$ is defined as follows:

$$
\delta_{i} \equiv\left(\frac{\Delta E_{i}^{V}}{V_{i}}\right)^{1 / 2}
$$

$\Delta E_{i}^{V}$ and $V_{i}$ are the evaporation energy and the molecular volume of Liquid $i$, respectively. When two kinds of liquids (Liquid 1 and Liquid 2) are mixed, the mixing energy is written using the respective solubility parameters, $\delta_{1}$ and $\delta_{2}$, as $\Delta U$ $=V_{v_{1} v_{2}}\left(\delta_{1}-\delta_{2}\right)^{1 / 2}$. Here, $V$ is the volume of the entire system, and $v_{1}$ and $v_{2}$ are the volume fractions of each liquid. This formula shows that materials will easily mix when the solubility parameters are nearly equal. This parameter is applicable when liquid infiltrates polymers. ${ }^{21)}$ Figure 7 shows the graph of solubility parameters of typical solvents and PDMS. The horizontal scale represents the magnitude of the parameters.

The solubility parameters of the mold material of PDMS and silicone oil used as the infiltrating liquid are the same value, 7.3 and that of the ethanol used as the solvent of the suspension is 12.7. The significant difference between the solubility parameters of the silicone oil and ethanol means $\gamma_{12}$ $\gg 0$. Besides, the differential of the solubility parameters of ethanol and silicon to that of PDMS, indicates $\gamma_{1}-\gamma_{2} \gg 0$. Therefore, silicone oil is considered adequate as the infiltrating liquid.

\section{Conclusion}

We improved the MIMIC process to pattern ceramic colloidal suspensions over a wide area by adding a second capillary step using a liquid with a high infiltration characteristic.
Furthermore, from the analysis of the solubility parameters, the highly volatile silicone oil used in the experiment was proved adequate as the infiltrating liquid. Although we used tin oxide as the powder of the suspension in this study, this process seems applicable to other kinds of powders, because this is the basis of the capillarity. However, there is a problem of nonuniformity for the lengths of the patterned lines as shown in Fig. $5(a-1)$.

Acknowledgements This work was supported by the Hosokawa Powder Technology Foundation and the Grant-inAid (Kiban B: \# 16350117) for Scientific Research from the Ministry of Education, Science, and Culture of Japan. The master molds used in this study were fabricated in the laboratory of Prof. Younan Xia in the Department of Chemistry, University of Washington (USA), and the PDMS molds were made in this laboratory. We greatly appreciate the cooperation of Prof. Xia.

\section{References}

1) Ozawa, N. and Yao, T., Solid State Ionics, Vol. 151, pp. 79-87 (2002).

2) Müller, C., Hanemann, T., Wiche, G., Kumar, C. and Goettert, J., Microsystem Technologies, Vol. 11, pp. 271-277 (2005).

3) Heitz, J., Pedarnig, J. D., Bäuerle, D. and Petzow, G., Appl. Phys. A, Vol. 65, pp. 259-261 (1997).

4) Zhao, X., Evans, J. R. G. and Edirisinghe, M. J., J. Am. Ceram. Soc., Vol. 85, pp. 2113-2115 (2002).

5) Akedo, J., Ichiki, M., Kikuchi, K. and Maeda, R., Sensors \& Actuators A, Vol. 69, pp. 106-112 (1998).

6) Beh, W. S., Xia, Y. and Qin, D., J. Mater. Res., Vol. 14, pp. 3995-4003 (1999).

7) Martin, C. R. and Aksay, I. A., J. Phys. Chem. B, Vol. 107, pp. 4261-4268 (2003).

8) Heule, M., Schell, J. and Gauckler, L. J., J. Am. Ceram. Soc., Vol. 86, pp. 407-412 (2003).

9) Ahn, S. J. and Moon, J., J. Am. Ceram. Soc., Vol. 88, pp. 1171-1174 (2005).

10) Zhao, X. M., Xia, Y. and Whitesides, G. M., J. Mater. Chem., Vol. 7, pp. 1069-1074 (1997).

11) Xia, Y. and Whitesides, G. M., Annu. Rev. Mater. Sci., Vol. 28, pp. 153-184 (1998).

12) Martin, C. R. and Aksay, I. A., J. Electroceramics, Vol. 12, pp. 53-68 (2004).

13) Kim, E., Xia, Y. and Whitesides, G. M., Nature, Vol. 376, pp. 581-584 (1995).

14) Kim, E., Xia, Y. and Whitesides, G. M., J. Am. Chem. Soc., Vol. 118, pp. 5722-5731 (1996).

15) Monahan, J., Gewirth, A. A. and Nuzzo, R. G., Anal. Chem., Vol. 73, pp. 3193-3197 (2001).

16) Hatton, B. D. and Sakka, Y., J. Am. Ceram. Soc., Vol. 84, pp. 666-668 (2001).

17) Doungdaw, S., Uchikoshi, T., Noguchi, Y., Eamchotchawalit, C. and Sakka, Y., Sci. Tech. Adv. Mater., Vol. 6, pp. 927-932 (2005).

18) Uchikoshi, T., Furumi, S., Suzuki, T. S. and Sakka, Y., J. Ceram. Soc. Japan, Vol. 114, pp. 55-58 (2006).

19) De Gennes, P. G. and Brochard-Wyart, F., (Quéré D., Okumura, K.,) "Gouttes, Bulles, Perles et ondes (Hyoumenchoryoku no Butsurigaku)," Yoshioka Shoten (2003) pp. 127-130 [in Japanese].

20) Yamamoto, H., "SP Chi Kiso-Ouyou to Keisanhouhou," Johokiko (2005) pp. 37-40 [in Japanese].

21) Ogino, K., Osada, Y., Fushimi, T. and Yamauchi, A., "GeruSofutomateriaru no Kiso to Ouyou-," Sangyotosho (2002) pp. 77-89 [in Japanese]. 